\title{
-Shakedown solutions for pavements with materials following associated and non-associated plastic flow rules
}

\author{
•Shu Liu ${ }^{1,2}$, Juan Wang ${ }^{2,3, *, t, ~ H a i-S u i ~ Y u 1, ~ D a r i u s z ~ W a n a t o w s k i ~}{ }^{1,3}$ \\ . The University of Nottingham, Nottingham, UK \\ .2 State Key Laboratory for GeoMechanics and Deep Underground Engineering, China University of Mining \& Technology \\ -3he University of Nottingham, Ningbo, China
}

-ABSTRACT: Existing lower-bound shakedown solutions for pavement problems are generally obtained by assuming that materials obey associated flow rules, whereas plasticity of real materials is more inclined to a non-associated flow. In this paper, a numerical step-by-step approach is developed to estimate shakedown limits of pavements with Mohr-Coulomb materials. In particular, influences of a non-associated flow rule on the shakedown limits are examined by varying material dilation angle in the numerical calculations. It is found that the decrease of dilation angle will lead to accelerated reduction of pavement shakedown limits, and the reduction is most significant when the material friction angle is high. Furthermore, existing lower-bound shakedown solutions for pavements are extended, in an approximate manner, to account for the change of material dilation angle and the shakedown results obtained in this way agree well with those obtained through the numerical step-by-step approach. An example of pavement designs using shakedown theory is also presented.

•Keywords: shakedown; pavements; non-associated flow rule; Mohr-Coulomb materials; lower-bound

\section{-1 INTRODUCTION}

-Current mechanistic-empirical design methods for flexible pavements are usually conducted by relating pavement life with elastic stress/strain at critical locations considering several principle failure modes. However, one of the failure modes, excessive rutting, is mainly caused by an accumulation of permanent deformation under repeated traffic loads. Therefore, a plastic design method using shakedown theory is considered more rational $[1,2]$. The shakedown theory can 
-distinguish the long-term elastic-plastic responses of a pavement to different levels of traffic loads. If the load level is high, pavements may fail in a form of excessive rutting as a result of accumulated permanent deformation. Alternatively, if the load level is low, the pavement may deform plastically in the first number of load passes, then respond purely elastically to subsequent traffic loads. The latter phenomenon is called 'shakedown', and the load below which shakedown can occur is termed as 'shakedown limit'. In the design of flexible pavements, the shakedown limit can be calculated and checked against the design traffic loads to ensure very small permanent deformations of pavements throughout their service lives. -The shakedown limit can be determined by either numerical elastic-plastic analysis (e.g. [3, 4]) or two fundamental shakedown theorems. Melan's static (lower-bound) shakedown theorem [5] states that an elastic-perfectly plastic structure under cyclic or variable loads will shakedown if a time-independent residual stress field exists such that its superposition with load-induced elastic stress field does not exceed yield criterion anywhere in the structure. Koiter's kinematic (upperbound) shakedown theorem [6] states that shakedown cannot occur for an elastic-perfectly plastic structure subjected to cyclic or variable loads if the rate of plastic dissipation power is less than the work rate of external forces for any admissible plastic strain rate cycle. In the past few decades, solutions for shakedown limits of pavements were developed mainly based on these two fundamental shakedown theorems. Several different approaches based on Melan's static shakedown theorem were developed for pavements subjected to two-dimensional (2D) and threedimensional (3D) moving surface loads [1, 3, 7-19]. Furthermore, kinematic shakedown analyses were carried out by using Koiter's shakedown theorem for 2D and 3D pavement [20-25]. It should be noted that the static and kinematic shakedown solutions provide lower and upper bounds to the true shakedown limit of a pavement respectively. This is because the lower-bound shakedown theorem satisfies internal equilibrium equations and stress boundary conditions, while the kinematic shakedown theorem satisfies compatibility condition for plastic strain rate and boundary conditions for velocity. Nevertheless, some identical upper and lower 
•bound solutions have been obtained. For instance, when a 2D Mohr-Coulomb half-space is subjected to a moving pressure, the lower-bound shakedown solutions (as obtained by Wang [3]) are identical to the upper-bound shakedown solutions (as obtained by Collins and Cliffe [21]). Although some converged shakedown limits have been obtained by using the static and kinematic shakedown theorems, they are calculated based on the assumption of an associated flow rule (i.e. the plastic strain rate is normal to the yield surface). It is well known that granular materials, such as soil and pavement materials, exhibit a non-associated plastic behaviour [26, 27]. Until now, very limited results have been reported on this topic. Boulbibane and Weichert [28] proposed a theoretical framework for shakedown analysis of soils with a non-associated plastic flow. It was reported by Nguyen [29] that this framework can be applied to shakedown analysis of footing problems. With the use of linear matching method, Boulbibane and Ponter were able to give 3D upper-bound shakedown solutions for DruckerPrager materials with zero dilation angle, but did not evaluate the influence of the change of dilation angle [22]. Numerical studies of $\mathrm{Li}$ [25] extended the 2D upper-bound shakedown solutions of $\mathrm{Li}$ and $\mathrm{Yu}$ [24] to the materials with non-associated plastic flow and suggested that the pavement upper-bound shakedown limit is reduced due to the use of non-associated flow rule. For practical pavement design, the influence of material plastic flow rule on lower-bound shakedown limits needs to be assessed.

-In this paper, first, shakedown limits for 2D pavement problems will be captured by using a step-by-step numerical approach. Both associated and non-associated flow rules will be considered for pavement materials. Then a direct method will be developed based on the previous work of Yu and Wang [16] to estimate the lower-bound shakedown limits of pavements using a non-associated plastic flow rule. 


\section{-2 PROBLEM DEFINITION}

-It is considered that a pavement is repeatedly subjected to a rolling long cylinder, as shown in Figure 1. This can be simplified as an idealised plane strain pavement model with a moving contact load $P$. The normal load distribution $p$ (refer to Figure 2) can be assumed as:

$$
\cdot p \cdot \nexists \rho \overline{\cdot 1\left(x^{\prime} /\right) \cdot{ }^{2}\left(x^{\prime}\right)} a \leq \leq a(\mathbf{1})
$$

-where $a$ is half of contact length; $p_{0}(=2 P / \pi a)$ is the maximum vertical stress located at $\mathbf{x}^{\prime}=\mathbf{z}^{\prime}$ $=0$. This load distribution is also known as 2D Hertz load distribution $[1,30]$.

\section{-3 NUMERICAL APPROACH}

-In this section, a numerical step-by-step approach for pavement shakedown problem is presented and validated. Results including shakedown limits, residual stresses and plastic strains are discussed in detail.

\section{•3.1 Method description}

\section{•3.1.1 Numerical approach}

-Shakedown solutions based on the lower-bound (static) shakedown theorem were obtained by assuming statically-admissible residual stress fields. It means the actual residual stress fields developed in pavements were not considered. In the present study, finite element (FE) elasticplastic analyses are carried out to obtain the actual residual stresses developed in pavement structures under repeated moving traffic loads. By using finite element software ABAQUS, shakedown limits of pavements can be obtained through a step-by-step approach:

- (1) As illustrated in Figure 2, for a given pavement structure, the load moves on the pavement surface repeatedly from point $B$ to point $C$. At the end of each load pass, the applied load is removed thoroughly to investigate stresses remaining in the pavement (known as residual stresses). 
2. After a few numbers of load passes, a static load with the same magnitude of the moving load is applied in the middle on the pavement surface. If no yielding point can be found in the pavement (i.e. the total stress state of each point in the pavement does not violate the yield criterion), a steady state (termed as 'shakedown state') is achieved. In contrast, any yielding point would indicate that the applied load is above the shakedown limit of the pavement and the whole structure is in a non-shakedown state.

1. Several numerical simulations with different load magnitudes are performed to determine the shakedown limit of the pavement.

-It should be noted this numerical approach requires great computation efforts in order to obtain results with a reasonable accuracy. This problem has been solved to a great extent by using High Performance Computing (HPC) facilities in the University of Nottingham, UK.
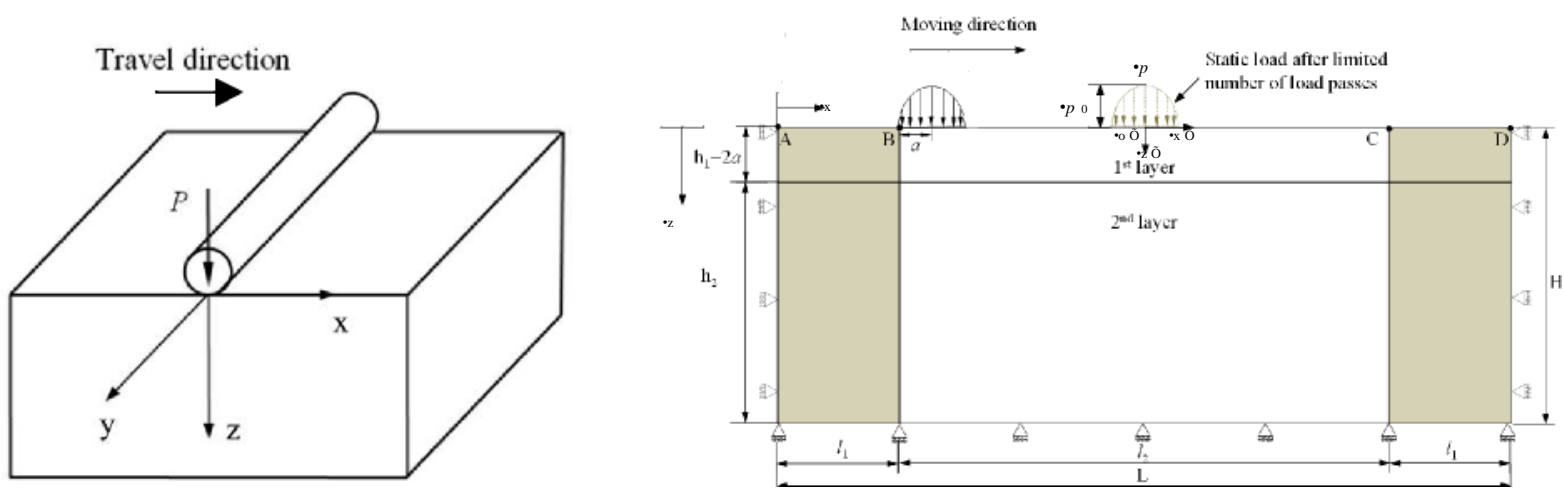

-Figure 1 Idealised pavement model Figure 2 Model sketch and boundary conditions and -2D Hertz load distribution

\section{-3.1.2 Model description}

-A pavement model is established using ABAQUS. During every load pass, the load is gradually applied at the start point, then translated in the horizontal direction at a constant speed, and finally removed at the end point. The loading process is controlled by a user subroutine DLOAD. The simulation is processed by means of 'automatic incrementation control' with a given maximum increment of 0.1. According to ABAQUS Analysis User's Guide [32], the stiffness matrix of the materials following associated plastic flow is automatically selected by the solver (symmetric or unsymmetric), while for non-associated cases, it is set to be unsymmetric 
-compulsively. Figure 2 shows a sketch of a two-layered pavement used in this study. A restraint on horizontal movement is applied at two vertical boundaries, and a restraint on vertical movements is applied on the bottom boundary. In order to minimise the influence of two vertical boundaries on numerical results, no load is applied near the vertical boundaries. Eightnoded, reduced-integrated, quadratic elements (CPE8R) are selected to avoid hour-glassing and interlocking problems. Material properties of each layer are described by linear elastic parameters (Young's modulus E and Poisson's ratio $v$ ) and Mohr-Coulomb criterion parameters (cohesion c, friction angle 0 and dilation angle $y i$ ). The materials are assumed to be homogenous, isotropic, and elastic-perfectly plastic with the associated plastic flow (i.e. $O=y i$ ) or a non-associated plastic flow (i.e. $0 \leq y i<0$ ). In this paper, subscript ' $\mathbf{n}$ ' of $\mathbf{E}, \boldsymbol{v}, \mathbf{c}, 0$ and $y i$ represents the $\mathrm{n}^{\text {th }}$ layer. For single-layered pavement problems, identical materials are assigned to both layers. In addition, tension is positive in the following results. It should be noted that the Mohr-Coulomb model in ABAQUS uses a smooth plastic flow potential proposed by Menetrey and Willam [31] which is very close to the classical Mohr-Coulomb model with faced flow potential, especially when mean pressure is high [32].

-The Drucker-Prager model with corresponding parameters transformed from MohrCoulomb parameters was also used to investigate the influence of material plasticity model. Results showed that these two models provide almost the same shakedown limits. For example, when $O=\mathbf{2 0 ^ { \circ }}$, the shakedown limits are 7.5c in the case of Mohr-Coulomb materials and 7.4c in the case of Drucker-Prager materials. Therefore, the Mohr-Coulomb model was selected in the following study.

\section{-3.1.3 Validation}

-Table 1 shows different model dimensions used for sensitivity study and their corresponding results. Model A was used by Wang and Yu [4] for homogenous half-space but required lots of computation efforts. From Model B and Model C, it can be seen that some reductions in height and length of the model only slightly change the shakedown limit while saving a lot of 
-computation time. Therefore, model dimensions of $40 a$ (length of loading area L) $x 25 a$ (depth H) are selected. As mentioned before, the no-loading areas were applied near vertical boundaries. Their influences were checked by Model D in which the moving load gradually entered through the left boundary and finally exited through the right boundary, and Model E in which the length of the no-loading area $\mathrm{L}^{\prime}$ is increased from $3 a$ to $10 a$. The results demonstrate the length of the no-loading area barely affects shakedown limits. However, for some two-layered cases, it was found that $L^{\prime}=3 a$ was not enough to prevent yielding near the vertical boundaries. Therefore, Model $\mathrm{E}$ is finally chosen.

-Sensitivity studies on mesh density were also carried out to ensure that mesh distribution can obtain numerical results with a reasonable accuracy. High mesh density is applied in the first layer and near the interface between two layers due to high stress and strain gradient. As shown in Table 2 , the shakedown limit barely changes when the number of elements exceeds 16000 for both single-layered and multi-layered model. Therefore, the mesh density in case 3 is selected. In this case, elements are distributed uniformly along $10 a \leq \mathbf{x} \leq \mathbf{5 0} a$ (the loading area) and small elements $(0.25 a \times 0.1 a)$ are applied in the region near the surface $(\mathrm{z} \leq 2 a)$. The mesh is also fine just beneath the interface, and it becomes coarser with increasing depth.

-Table 1 Influence of model dimension $\left(!=\psi=20^{0}, v=0.3\right)$

\begin{tabular}{lcccccc} 
Model No. & L & H & $\mathbf{L}^{\prime}$ & $\begin{array}{c}\text { Theoretical } \\
\text { shakedown limit }\end{array}$ & $\begin{array}{c}\text { Numerical } \\
\text { shakedown limit }\end{array}$ & $\begin{array}{c}\text { Average elapsed time per } \\
\text { load pass (s) }\end{array}$ \\
\hline A & $\mathbf{7 8} a$ & $\mathbf{3 0} a$ & $\mathbf{3} a$ & & $\mathbf{7 . 5 c}$ & $\mathbf{1 3 8 5 4}$ \\
B & $\mathbf{4 0} a$ & $\mathbf{3 0} a$ & $\mathbf{3} a$ & $\mathbf{7 . 4 c}$ & $\mathbf{3 6 0 7}$ \\
$\mathbf{C}$ & $\mathbf{4 0} a$ & $\mathbf{2 5} a$ & $\mathbf{3} a$ & $\mathbf{7 . 5 6}$ & $\mathbf{7 . 4 c}$ & $\mathbf{3 5 7 6}$ \\
D & $\mathbf{4 0} a$ & $\mathbf{2 5} a$ & $\mathbf{0}$ & & $\mathbf{7 . 5 c}$ & $\mathbf{3 4 8 0}$ \\
E & $\mathbf{4 0} a$ & $\mathbf{2 5} a$ & $\mathbf{1 0} a$ & & $\mathbf{7 . 5 c}$ & $\mathbf{3 4 7 5}$ \\
\hline
\end{tabular}

-Table 2 Influence of mesh density

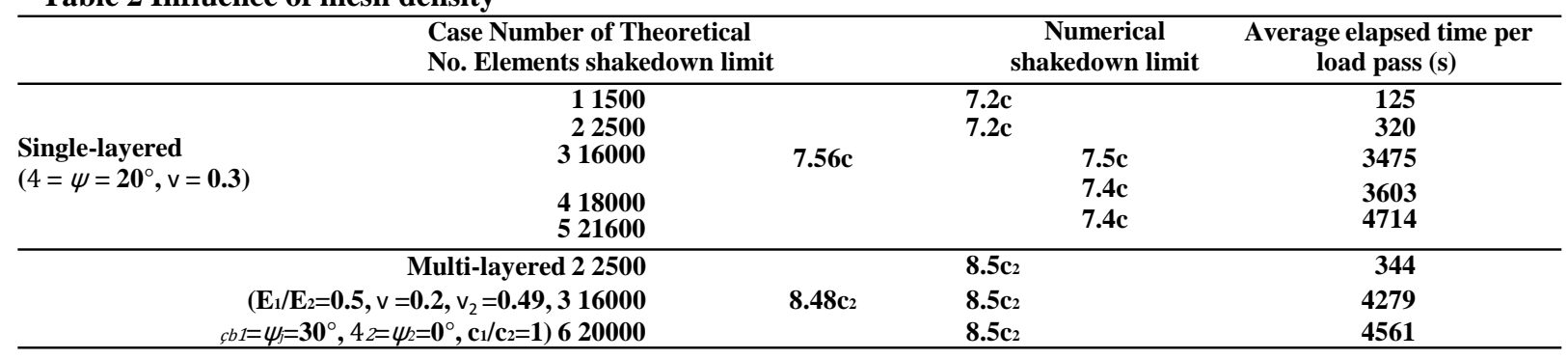

$\mathbf{E}_{1} / \mathbf{E}_{2} \quad \mathbf{c}_{1} / \mathbf{c}_{2} \quad$ Shakedown limit




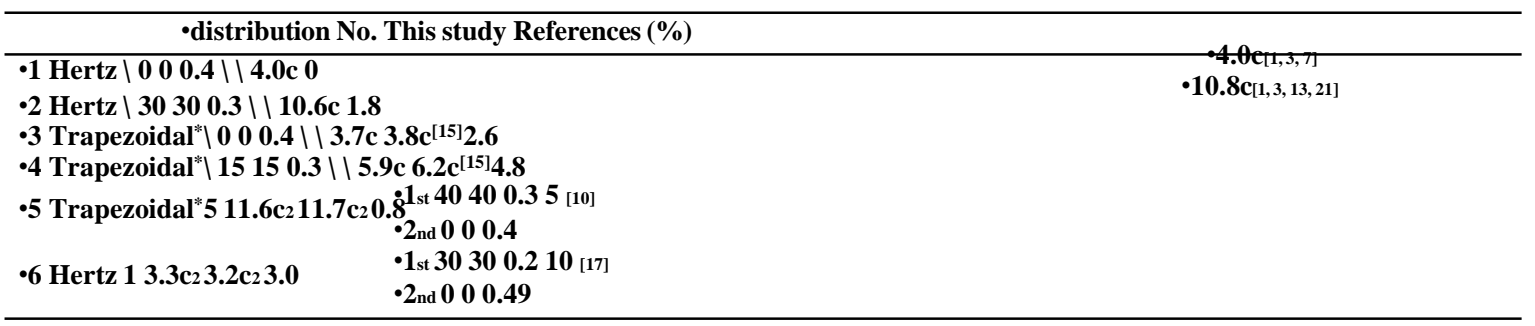

${ }^{*} b \mathbf{I} a=0.5$ where $a$ and $b$ are the lengths of the lower and upper sides of trapezoid; Cases 1-4 are for single-layered pavements and cases 56 are for two-layered pavements

-Shakedown limits obtained by the current approach are also compared with shakedown solutions of other researchers. Those shakedown solutions were developed based on the classical shakedown theorems and they all assumed that an associated plastic flow rule is applied to pavement materials. Table 3 demonstrates that the differences between shakedown limits of the current study and those in references are within $4.8 \%$.

\section{-3.2 Single-layered pavements}

-Table 4 presents numerical results for single-layered pavements and compares them with the shakedown limits of Wang [3]. If an associated flow rule $(\phi=\psi)$ is assumed, the shakedown limits are only slightly lower than those in Wang [3] with a maximum difference of $2.0 \%$. However, if a non-associated flow rule $(\psi<\phi)$ is used in the numerical model, the difference can be as high as 13.1\%. Therefore, the effect of plastic flow rule cannot be neglected, especially when the friction angle is high. Also, Table 4 exhibits that the dimensionless shakedown limit (defined as the shakedown limit normalised by material cohesion ' $c$ ') accelerated reduces with decreasing dilation angle, and the maximum reduction occurs when the dilation angle $\psi$ drops from $30^{1 / 4}$ to $\mathbf{0}^{\circ}$ (friction angle $\phi$ remains $30^{\circ}$ ).

-Table 4 Material parameters and shakedown limits for single-layered pavements

\begin{tabular}{|c|c|c|c|c|c|c|}
\hline Case No. & $\phi\left({ }^{\circ}\right)$ & $\psi\left({ }^{\circ}\right)$ & $v$ & Theoretical shakedown limit & Numerical Shakedown limit & Difference $(\%)$ \\
\hline 1 & 30 & 30 & 0.3 & $10.82 \mathrm{c}$ & $10.6 c$ & 2 \\
\hline 2 & 30 & 20 & 0.3 & & $10.4 \mathrm{c}$ & 3.8 \\
\hline 3 & 30 & 10 & 0.3 & & $10.0 \mathrm{c}$ & 7.6 \\
\hline 4 & 30 & $\mathbf{0}$ & 0.3 & & $9.4 c$ & 13.1 \\
\hline 5 & 20 & 20 & 0.3 & $7.56 \mathrm{c}$ & $7.5 \mathrm{c}$ & 0.8 \\
\hline 6 & 20 & 10 & 0.3 & & $7.4 \mathrm{c}$ & 2.1 \\
\hline 7 & 20 & $\mathbf{0}$ & 0.3 & & $7.2 \mathrm{c}$ & 4.8 \\
\hline 8 & 15 & 15 & 0.3 & $6.58 \mathrm{c}$ & $6.1 \mathrm{c}$ & 7.3 \\
\hline 9 & 15 & 7.5 & 0.3 & & 6.1c & 7.3 \\
\hline 10 & 15 & 0 & 0.3 & & $6.1 \mathrm{c}$ & 7.3 \\
\hline
\end{tabular}


-According to the lower bound shakedown theorem, residual stress field $\sigma_{\mathrm{ij}}$ ( $\mathrm{i}$ and $\mathbf{j}$ denote $\mathbf{x}$ axis or $\mathbf{z}$ axis) plays an important role in helping structures reach the shakedown state. Ideally, elements at the same depth should experience the same loading history; therefore the resulting residual stress distribution should be independent of $x$ axis [16]. Johnson [7] noted that ${ }_{\text {axzr }}$ and azz ${ }^{r}$ should be zero for the $2 \mathrm{D}$ pavement problem due to the self-equilibrium condition. This was verified by Wang [3] by numerical approach. Previous researches $[3,4,34]$ demonstrated that residual stresses in pavements under moving surface loads barely change after several load passes, no matter the load applied is at or above the shakedown limit. It coincides with the test report of Radovsky and Murashina [33] in which the measured residual stresses cease to increase after 12 wheel passes. In consideration of the non-associated plastic flow, similar phenomenon is also observed (Figure 3). Lower load level results in smaller amounts of residual stresses. When the load magnitudes remain the same, the fully-developed residual stresses are also compared in Figure 4(a) for the case of $\phi=30_{i}$ and $p_{0}=10.6 \mathrm{c}$. Wang [3] also noted that the actual horizontal residual stress field ${ }_{\text {axxr }}$ should lie between two critical residual stress fields (referred to as 'minimum larger root (MLR)' and 'maximum smaller root (MSR)') when the applied load is no larger than the shakedown limit. Figure 4(b) further compare those residual stresses with MLR and MSR when $0 \leq z / a \leq 1$. It is evident that the numerical residual stresses are completely bracketed by MLR and MSR when the materials obeying the associated flow rule. It can also be observed that the use of smaller dilation angle drifts some residual stresses further away from the safe region bracketed by two curves. Therefore there are some critical depths below the pavement surface representing locations for unlimited increasing plastic strains (Figures 5(a), 6(a)). If the load magnitude is higher than the shakedown limit, the structure will eventually fail due to excessive cumulative permanent deformation. However, if the load magnitude is reduced to the shakedown limit, plastic strains will cease to accumulate after a few load passes (Figures 
•5(b), 6(b)). This is because smaller load magnitude will result in wider safe region between two curves, so that the fully-developed horizontal residual stress field can be well contained.

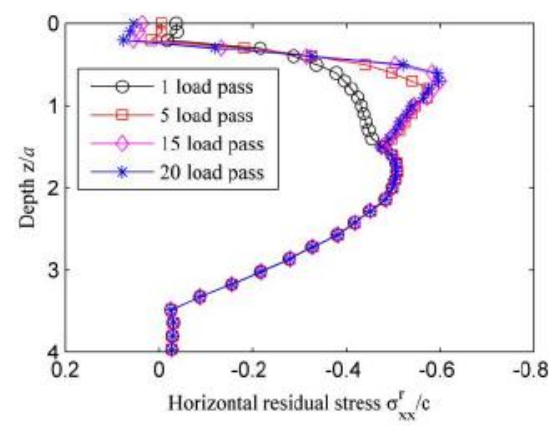

(a) $\phi=30^{\circ}, \psi=20^{\circ}, p_{0}=10.4 \mathrm{c}$

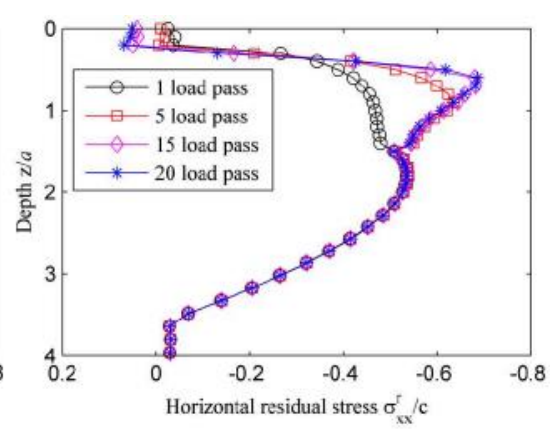

(b) $\phi=30^{\circ}, \psi=20^{\circ}, p_{0}=10.6 \mathrm{c}$

-Figure 3 Development of horizontal residual stress field
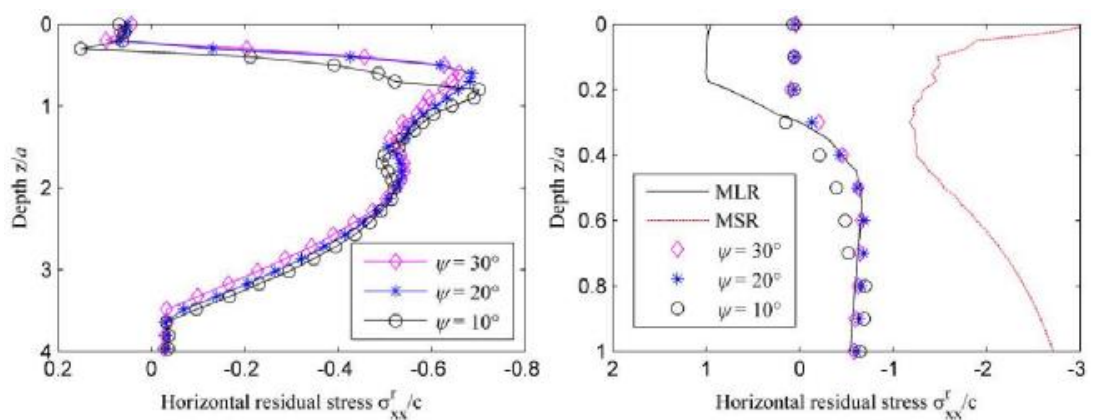

•(a) (b)

-Figure 4 Influence of dilation angle on horizontal residual stress field when $\varphi=30^{\circ}, P 0=10.6 c$

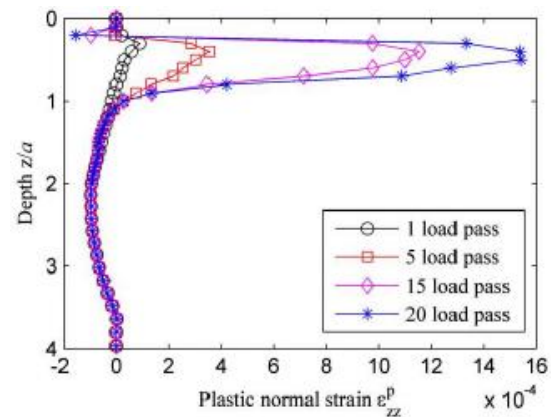

(a) $\phi=30^{\circ}, \psi=10^{\circ}, p_{0}=10.6 \mathrm{c}$

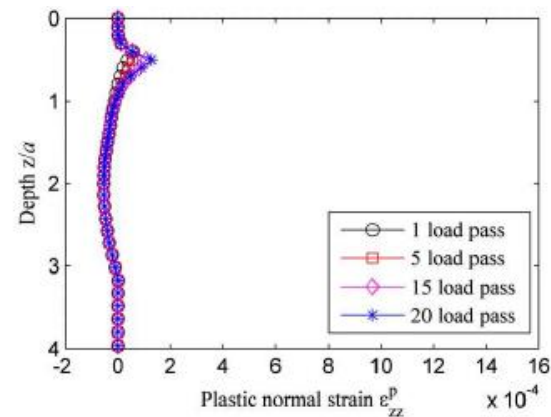

(b) $\phi=30^{\circ}, \psi=10^{\circ}, p_{0}=10.0 \mathrm{c}$

-Figure 5 Development of plastic normal strains 


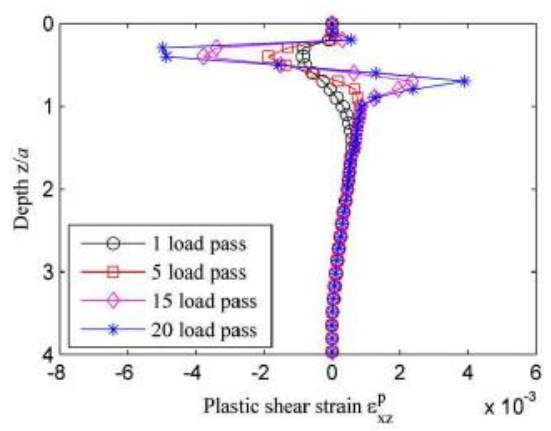

(a) $\phi=30^{\circ}, \psi=10^{\circ}, p_{0}=10.6 \mathrm{c}$

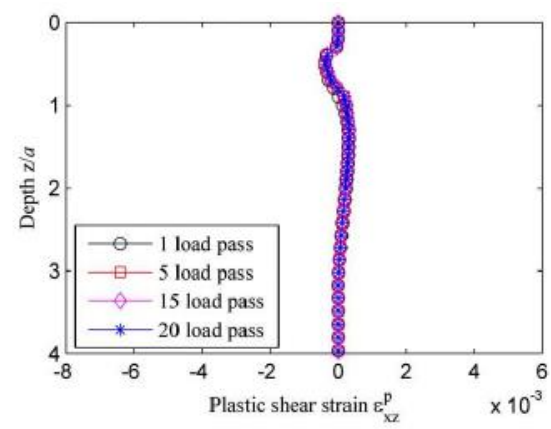

(b) $\phi=30^{\circ}, \psi=10^{\circ}, p_{0}=10.0 \mathrm{c}$

-Figure 6 Development of plastic shear strains

-3.3 Multi-layered pavements

-A two-layered pavement structure with $h_{1}=2 a, c_{:_{1}}=30_{i}, v_{1}=0.2, E_{2}=\psi_{2}=0_{i}, v_{2}=0.49$ is taken as an example for analyses. Results are obtained by using materials with either an associated flow rule $\left(\varnothing_{1}=\psi_{1}=3^{0}\right)$ or a non-associated flow rule $\left(\varnothing_{1}=30^{1 / 4} \psi_{1}=0^{0}\right)$. A direct comparison between these two cases is made in Figure 7 for various stiffness ratios E1/E2. Shakedown limits calculated through lower-bound approach of Wang and Yu [17] are also presented in this figure as a dash line. In the present study, shakedown limit of any layer in a multi-layered pavement is normalised by the cohesion of the second layer ${ }_{c 2 .}$ It is noteworthy that there exists an optimum stiffness ratio at around $\mathrm{E}_{1} / \mathrm{E}_{2}=1.4$ at which the shakedown limit is maximised. The turning point also indicates the change of pavement failure mode from second layer failure to first layer failure. As can be seen, numerical results for cases with associated flow rule agree well with the lower-bound shakedown limits. However, when the nonassociated flow rule is applied, numerical results are lower than the lower-bound shakedown solutions when $E_{1} / E_{2} \geq 0.8$. More results for multi-layered pavements with materials following associated flow rule can be found in Liu et al. [34]. 


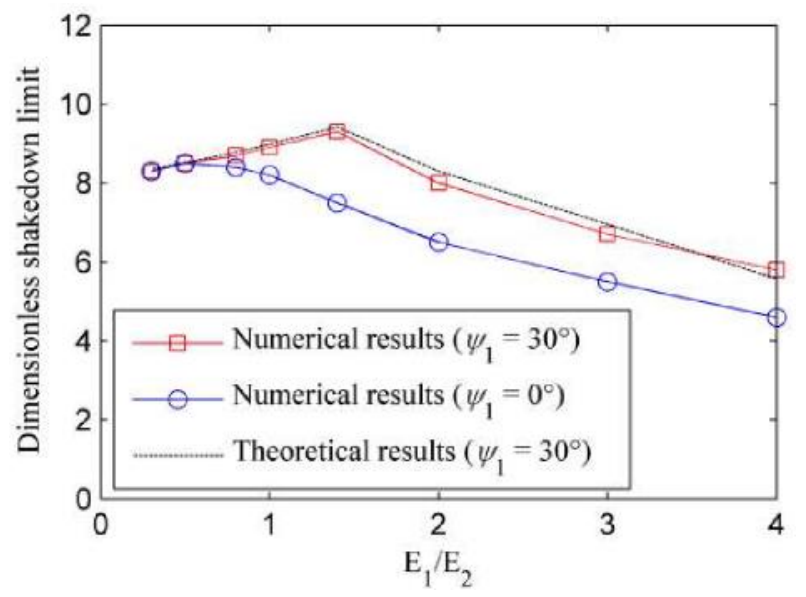

-Figure 7 Comparison of numerical and theoretical shakedown limits for layered pavements when $\varphi_{1}=30^{0}, \varphi_{2}=0^{0}$, $\cdot \mathbf{c}_{1} / \mathbf{c}_{2}=\mathbf{1}$

-Residual stresses also develop in multi-layered pavements. Taking a two-layered pavement as an example, the fully-developed horizontal residual stress field exists not only in the first layer, but also at the top of the second layer, as shown in Figure 8(a). This means that the top of the second layer can also be critical. This agrees with the current pavement design approach (e.g. [35]) in which the top of soil subgrade is considered as one of the critical locations. Again, with the use of non-associated flow rule, some fully-developed residual stresses cannot reach the safe region bracketed by MLR and MSR. Therefore, shakedown limits of the non-associated cases are smaller than those using $\emptyset_{1}=\psi 1$. Further studies show that for the pavement with $\emptyset_{1=30}{ }^{1 / 4}$ $\psi 1=0^{0}$, if the load is decreased from $6.7 \mathrm{c}_{2}$ to $5.5 \mathrm{c}_{2}$, the numerical residual stresses can totally lie within the safe region, as shown in Figure 8(b), and therefore the pavement will shake down to a steady state.

-In sum, the numerical approach is a valid way to obtain shakedown limits of pavements with the assumptions of either an associated or a non-associated plastic flow rule. More numerical solutions considering different load cases, strength ratios and layer configurations will be presented in the following section in comparison with theoretical solutions. 


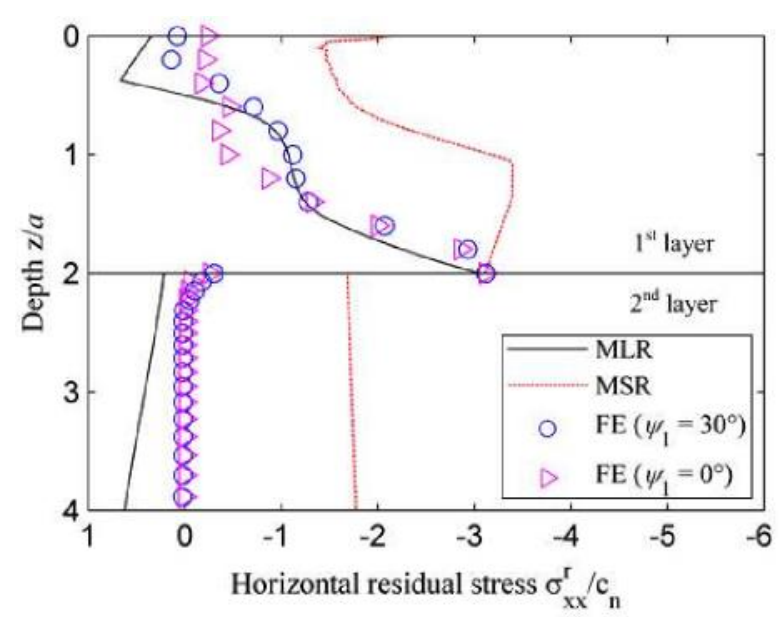

(a) $p_{0}=6.7 \mathrm{c}_{2}$

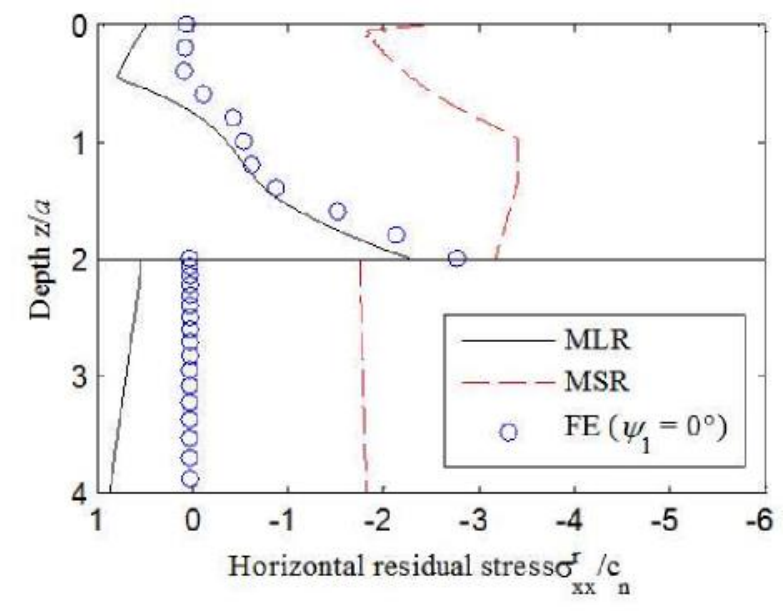

(b) $p_{0}=5.5 \mathrm{c}_{2}$

Figure 8 Comparison between FE calculated residual stress field and critical residual stress fields when $\varphi_{1}=300, \varphi_{2}=\psi_{2}=\mathbf{0}_{\mathbf{i}}$, $\mathbf{E}_{1} / \mathbf{E}_{2}=3$

\section{-4 LOWER-BOUND SHAKEDOWN SOLUTIONS}

-The classical shakedown theorems follow the principle of maximum plastic work. Therefore, shakedown solutions using classical shakedown theorems were based on the assumption of associated flow rule. However, as explained in the previous section, ignorance of non-associated plastic flow may overestimate the real shakedown limits of pavements thus lead to an unsafe pavement design. The numerical approach developed in the previous section has been devoted to overcome this issue. Despite much effort, very limited results have been reported in this aspect due to computation cost. A direct method to address this issue would be more appealing for practitioners. For this purpose, lower-bound shakedown solutions of Yu and Wang [16] will be further developed in this section to obtain approximate shakedown limits for pavements assuming non-associated plastic flow.

\section{-4.1 Shakedown analyses}

•Shakedown solutions of Yu and Wang [16] were developed based on Melan's lowerbound shakedown theorem. Assuming Mohr-Coulomb materials following associated flow rule, shakedown condition of the pavement problem can be written as[16]: 


$$
\begin{aligned}
& \leq \quad f=\mathrm{xx}++ \\
& \left(\sigma^{\mathrm{r} M}\right)^{2} \mathrm{~N} \mathrm{O}_{(2)}
\end{aligned}
$$

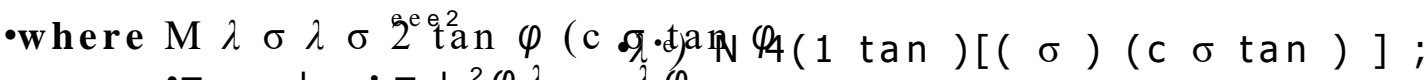
$\cdot=\mathrm{xx}-+-;=+{ }^{2} \varphi \lambda--\lambda \varphi$ $\cdot z z \mathrm{zz} x \mathrm{zz}$

- $\sigma_{\mathrm{xx}}$ is self-equilibrated residual stress field; $L$ is a scale parameter; ${ }^{\mathrm{e}}$

- $\sigma_{\mathrm{ij}}$ is the elastic stress field

due to applied unit pressure $p$; $f$ is Mohr-Coulomb yield function. This problem then can be solved by using a mathematical formulation developed in Yu and Wang [16].

-In consideration of non-associated plastic flow, the dilation angle $\psi(0 \leq \psi<\varphi)$ should be used. Davis [36], Drescher and Detounay [37], Sloan [38] suggested the use of reduced strength $\left(\varphi^{*}\right.$ and $\left.c^{*}\right)$ for the calculation of limit loads of structures in the case of materials obeying non-associated flow rule. And it has been used for stability analysis of plane strain footing problem (e.g. [37, 39-41]) in which:

$$
\begin{aligned}
& \text { - } \tan \varphi^{*}={ }_{\eta} \tan \varphi,(3)
\end{aligned}
$$

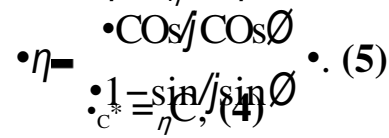

-By replacing $\varphi$ and $\mathrm{c}$ in Eq. (2) with $\varphi^{*}$ and $\mathrm{c}^{*}$ and using a similar solution procedure in Yu and Wang [16], shakedown limits of pavements $\lambda_{8 d} p_{0 u}$ with Mohr-Coulomb materials following •non-associated flow rule (defined by $\varphi, \psi$, c) can be found by searching through every point i at each depth $z=\mathbf{j}$ in the half-space for the maximum value of $) L$ in the following mathematical formulation:

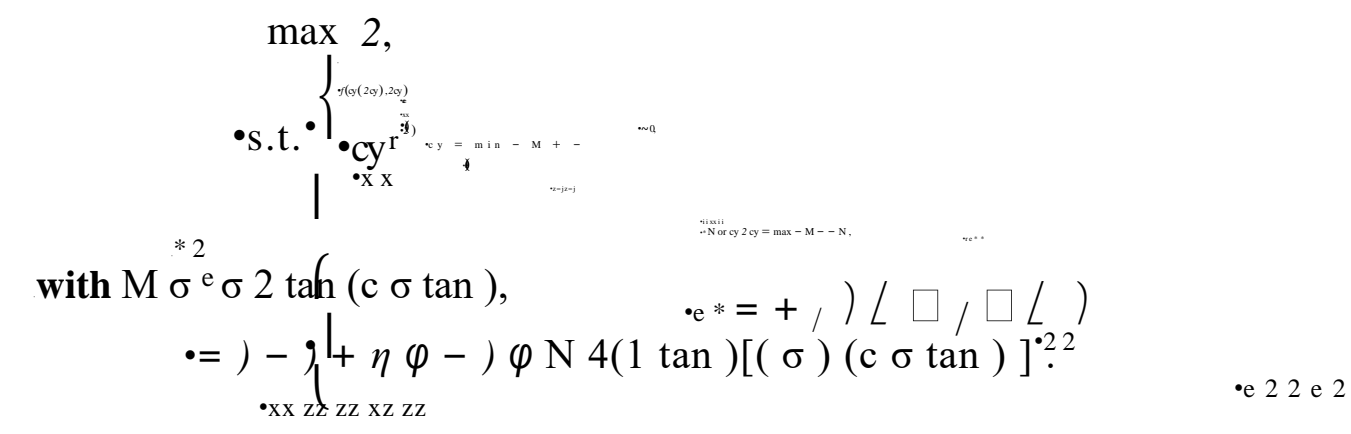




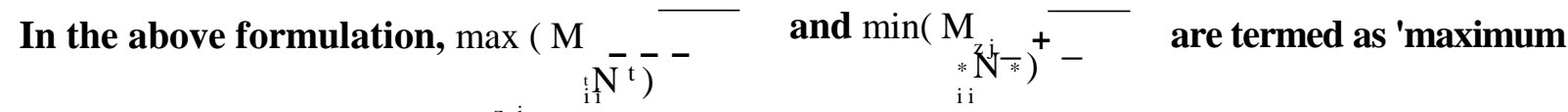
-smaller root (MSR)' and 'minimum larger $\operatorname{root}\left(\mathrm{ML}^{\mathrm{L}} \mathrm{L}\right)$ ' $\operatorname{respectively.~Any~residual~stress~field~}$ lying on or within the region bracketed by the MSR and MLR is a necessary condition for this shakedown problem, because they are obtained by satisfying the equilibrium and boundary conditions only. The actual residual stress field in a pavement should also be related with material plastic deformation which is affected by loading history. It is also interesting to notice that (e.g. Figure 4(b) and Figure 8), the actual residual stresses within the plastic region are very close to the compressive (negative) MLR rather than MSR. This implies that the structure tends to make a minimum plastic work (i.e. as small plastic deformation as possible) subject to a certain level of load in order to achieve the shakedown state. Outside the plastic region, the actual residual stresses are almost zero; whereas the MLR are positive. This is because the assumption of yielding at all depths [16] yields some positive artificial residual stresses. In reality, actual stress states at some depths will not touch the yield surface, reflected as zero residual stresses.

\section{-4.2 Results and comparison}

\section{-4.2.1 Single-layered pavements}

-A homogeneous half-space subjected to a moving 2D Hertz load is considered in this section and the shakedown limit is usually denoted as a dimensionless parameter $k=\lambda_{\text {sdpou }} / \mathrm{c}$. Figure 9 compares dimensionless lower-bound shakedown limits with those obtained from numerical approach and upper-bound solutions of $\mathrm{Li}$ [25] for various values of friction angle and dilation angle. The results generally agree except the cases with high friction angle and low dilation angle. This kind of discrepancy is also noted by other researchers (e.g. [38, 41]) when using the modified Mohr-Coulomb parameters $\left(\varphi^{*}\right.$ and $\left.c^{*}\right)$ to solve limit state problems. 


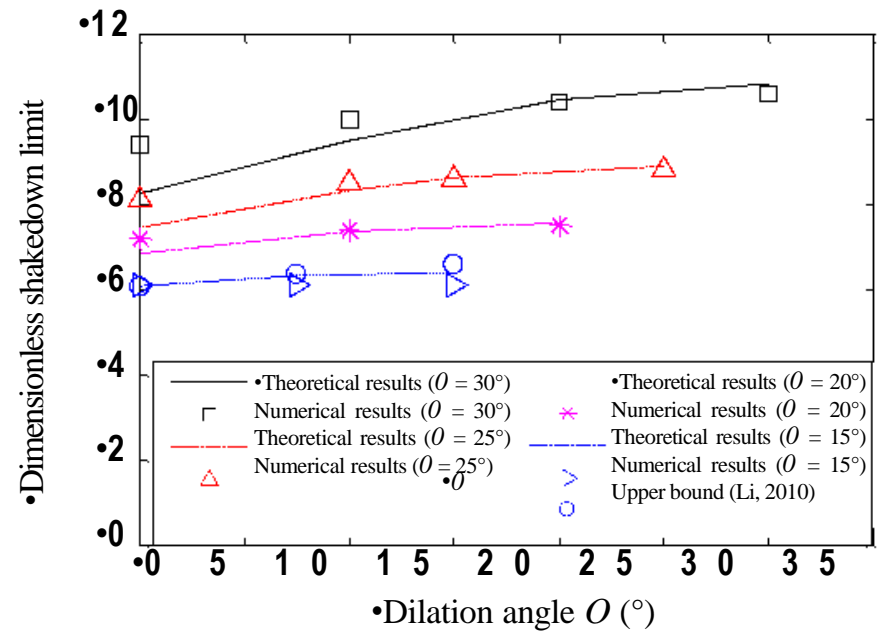

-Figure 9 Comparison of theoretical and numerical shakedown limits for single layered pavements

-Table 5 Dimensionless lower-bound shakedown limit parameters

\begin{tabular}{|c|c|c|c|c|c|c|c|c|c|c|}
\hline$\varphi$ & $y f=\mathbf{0}^{\circ}$ & $y f=\mathbf{5}^{\circ}$ & $y f=\mathbf{1 0}^{\circ}$ & $y f=15^{\circ}$ & $y f=\mathbf{2 0}^{\circ}$ & $y f=\mathbf{2 5}^{\circ}$ & $y f=\mathbf{3 0}^{\circ}$ & $y f=\mathbf{3 5}^{\circ}$ & $y f=40^{\circ}$ & $y f=\mathbf{4 5}^{\circ}$ \\
\hline $\mathbf{0}^{\circ}$ & 4.00 & & & & & & & & & \\
\hline $5^{\circ}$ & 4.64 & 4.66 & & & & & & & & \\
\hline $10^{\circ}$ & 5.34 & 5.42 & 5.45 & & & & & & & \\
\hline $15^{\circ}$ & 6.08 & 6.25 & 6.36 & 6.40 & & & & & & \\
\hline $20^{\circ}$ & 6.84 & 7.14 & 7.36 & 7.51 & 7.56 & & & & & \\
\hline $25^{\circ}$ & 7.58 & 8.03 & 8.43 & 8.73 & 8.93 & 9.00 & & & & \\
\hline $30^{\circ}$ & 8.25 & 8.90 & 9.50 & 10.02 & 10.44 & 10.72 & 10.82 & & & \\
\hline $35^{\circ}$ & 8.81 & 9.67 & 10.51 & 11.31 & 12.03 & 12.62 & 13.02 & 13.16 & & \\
\hline $40^{\circ}$ & 9.21 & 10.28 & 11.39 & 12.51 & 13.60 & 14.60 & 15.44 & 16.02 & 16.24 & \\
\hline $45^{\circ}$ & 9.41 & 10.68 & 12.05 & 13.51 & 15.03 & 16.53 & 17.96 & 19.19 & 20.06 & 20.39 \\
\hline
\end{tabular}

-More dimensionless shakedown limit parameters are shown in Table 5 for the problem of homogeneous Mohr-Coulomb half-space subjected to moving pressure. They can be expressed as an analytical form:

$$
k=\underset{\mathrm{q}_{\mathrm{z}}^{\mathrm{e}}}{\eta}+\eta \sigma_{\mathrm{zz}}^{\mathrm{e}} \tan \varphi
$$

-If this fictitious material (Eqs. (3)-(5)) is also applied to the upper bound shakedown solution of Collin and Cliffe [21] where a tangential velocity jump $v \cos \varphi$ is assumed, their solutions will -give the same shakedown

limits. 4.2.2 Multi-layered

pavements

-Comparisons between lower-bound shakedown limits and numerical results for layered pavements (with $h 1=2 a$ ) with various stiffness ratios also show good agreements in Figure 10 . Materials of the first layer have a friction angle $O=30^{\circ}$ and a dilation angle $y f=30^{\circ}$ or $0^{\circ}$, while the second layer is Tresca material (i.e. $O=y f=0^{\circ}$ ). It should be noted: (1) shakedown limit of 
•the pavement structure is the minimum one among shakedown limits of all layers, and therefore the turning point indicates the change of failure mode from one layer failure to another layer failure; (2) The change of first layer dilation angle only changes static shakedown limits of the first layer. When the first layer dilation angle is decreased from $30 ;$ to $0^{0}$, lower-bound shakedown limits of the first layer are well reduced. Since theoretical shakedown limits of the second layer does not change, the turning points of non-associate cases are deviated from those of associated cases. Therefore, the shakedown limits for non-associated cases are smaller than those for associated cases when $\mathrm{E} 1 / \mathrm{E} 2_{2}$ is relatively large $\left(\mathrm{E}_{1} / \mathrm{E}_{2} \geq 0.8\right.$ in Figure 10$)$, but remain the same when $_{\mathrm{E} 1 / \mathrm{E} 2}$ is small enough or $\mathrm{c1/ \textrm {c } 2}$ is large enough.

-Two more models with $h_{1}=3 a$ and $5 a$ were established to evaluate the effect of layer configuration on shakedown limits. As shown in Figure 11, the numerical shakedown limits show good agreements with lower-bound shakedown limits when an associated plastic flow rule is assumed. For non-associated cases, the numerical shakedown limits generally agree with the lower-bound shakedown limits when $h_{1} / a=2$ and $h_{1} / a=3$. When the first layer is relatively thick (i.e. $h_{1} / a=5$ ), the difference between theoretical and numerical solutions become obvious with decreasing dilation angle. Indeed, the increase of the first layer thickness leads to even more similar results to the homogeneous case. -In sum, when the dilation angle is at or above one third of the friction angle or the friction angle is relatively low, the numerical and theoretical results generally agree well. Noticeable discrepancy occurs when the friction angle is high while the dilation angle is very small in a homogeneous or homogenous-like structure. 


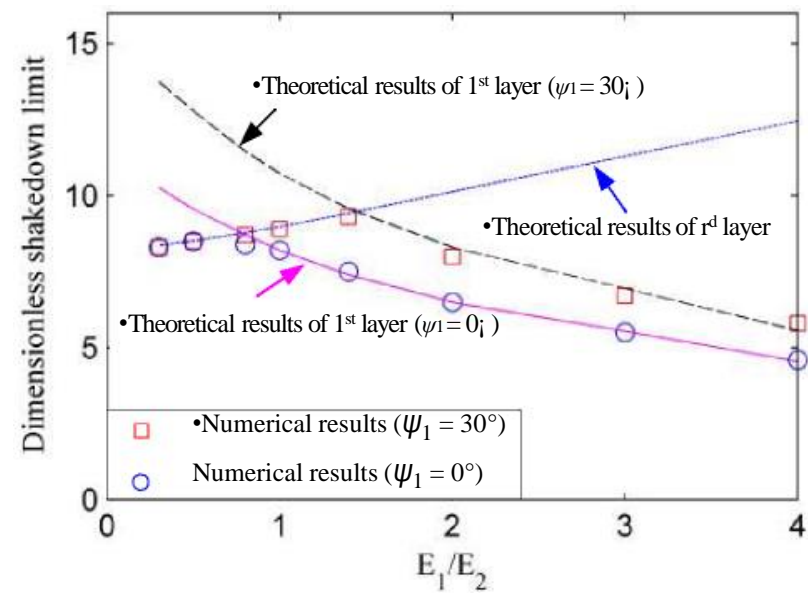

-Figure 10 Comparison of theoretical and numerical shakedown limits with varying stiffness ratio when $\mathrm{O}_{1}=30^{\circ}, \mathrm{O}_{2}$ $\cdot=\psi / 2=\mathbf{0}^{\circ}, \mathbf{c}_{1} / \mathbf{c}_{2}=\mathbf{1}$

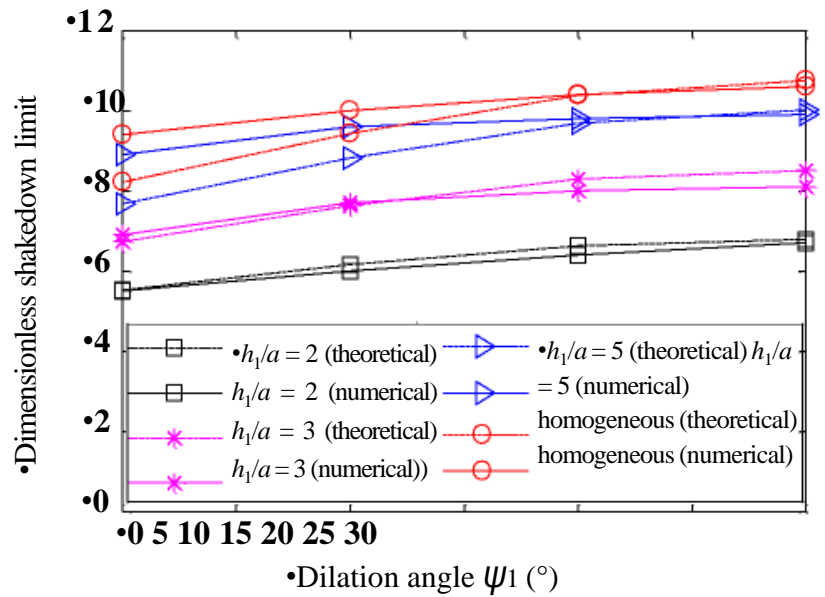

-Figure 11 Comparison of theoretical and numerical shakedown limits in two-layered pavements with varying first layer thickness when $\mathrm{O}_{1}=30^{\circ}, \mathrm{O}_{2}=\psi_{2}=\mathrm{O}^{\circ}, \mathrm{E}_{1} / \mathrm{E}_{2}=3, \mathrm{c}_{1} / \mathrm{c}_{2}=1$

\section{-4.2.3 Pavement design}

-Design of layered pavements can be carried out through a thickness chart such as Figure 12. Given elastic and plastic parameters of materials $\left(\mathbf{E}_{\mathbf{n}}, v_{\mathbf{n}}, 0_{\mathbf{n}}, \psi_{\mathbf{n}}, \mathbf{c}_{\mathbf{n}}\right)$, shakedown limits for different first layer thicknesses can be determined from this chart and compared against the design load. Finally, the thicknesses which can provide sufficient resistance to the maximum design load (i.e. the shakedown limit is higher than the maximum design load) should be selected. Compared with the results obtained using the assumption of $\varphi_{n}=\psi_{n}$, to sustain the same traffic load, thicker pavement layers are required. 


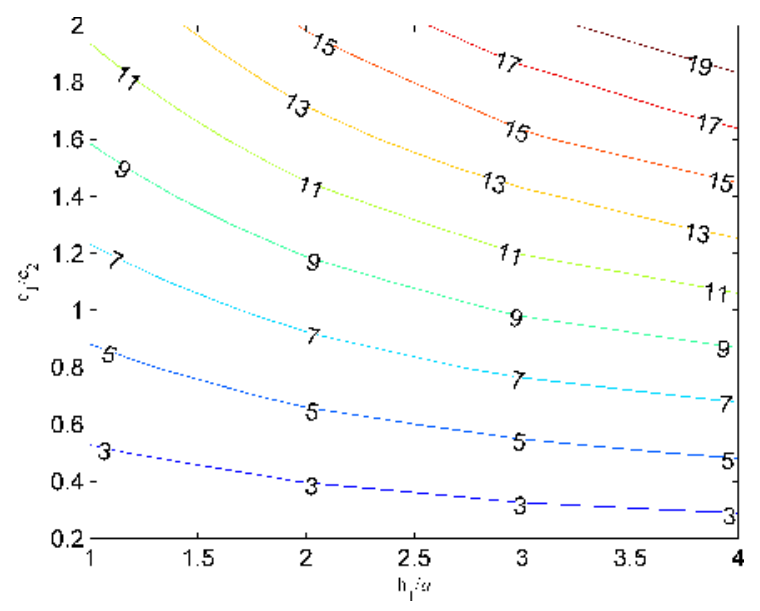

Figure 12 Contour of dimensionless shakedown limits as an example chart for the

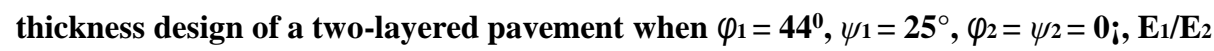
$=\mathbf{3}$

\section{-5 CONCLUDING REMARKS}

-In this paper, a numerical step-by-step approach and a lower-bound (static) shakedown approach have been developed to obtain shakedown limits of single-layered and multi-layered pavements assuming either an associated or a non-associated flow rule. Some important findings are summarised as follows:

1. The numerical approach presented in this paper is capable of obtaining shakedown limits of single-layered or multi-layered pavements with either an associated or a non-associated flow rule. 2. Compared with associated cases, the use of a non-associated flow rule obviously affects the distribution of residual stress fields and therefore leads to a smaller shakedown limit. If the friction angle is small or the difference between friction angle and dilation angle is small, the variation of dilation angle will only slightly change the shakedown limit of the pavement. Otherwise, the induced difference can be as high as $\mathbf{2 0 . 7 \%}$. Therefore, the influence of nonassociated plastic flow on the shakedown limit cannot be neglected, especially for materials with zero dilation angles.

3. The fully-developed residual stress field obtained from the numerical approach is bound by two critical residual stress fields (i.e. MLR and MSR) when the pavement is in the shakedown state. In both associated and non-associated cases, the fully-developed residual stress field is 
-very close to MLR rather than MSR in the plastic region. This implies that a principle of minimum plastic work may be applied when the structure tries to reach a shakedown state. (4) Static shakedown solutions for pavements with materials obeying non-associated flow rule have been developed by assuming fictitious materials with reduced strength. The results agree with most shakedown limits obtained from the numerical approach and upper bound solutions of $\mathrm{Li}$ [24]. When the dilation angle is much smaller than the friction angle (e.g. $\varphi=30 ;$ and $\psi=$ $\left.0^{0}\right)$, the present shakedown solutions may underestimate shakedown limits of pavements.

Nevertheless, as a method to solve the pavement shakedown problem, the direct static

•shakedown solutions can be very useful for conservative pavement design.

\section{•ACKNOWLEDGEMENTS}

-Financial supports from the National Natural Science Foundation of China (Grant Nos.

51408326 and 51308234), the State Key Laboratory for GeoMechanics and Deep Underground Engineering, China University of Mining \& Technology (Grant No. SKLGDUEK1411) and the University of Nottingham are gratefully acknowledged. We are also grateful for access to the University of Nottingham High Performance Computing Facility.

\section{-REFERENCES}

1. Yu HS. Three-dimensional analytical solutions for shakedown of cohesivefrictional materials under moving surface loads. P Roy Soc A-Math Phy 2005; 461 (2059) : 1951-1964.

2. Brown SF, Yu HS, Juspi H, Wang J. Validation experiments for lower-bound shakedown theory applied to layered pavement systems.Geotechnique 2012; 62 : 923-932. 3. Wang J. Shakedown analysis and design of flexible road pavements under moving surface loads. Ph.D. thesis, The University of Nottingham, UK, 2011.

4. Wang J, Yu HS. Residual stresses and shakedown in cohesive-frictional half-space under moving surface loads.Geomechanics and Geoengineering 2013a; 8 (1) : 1-14.

5. Melan E. Der spannungszustand eines hencky-mises'schen kontinuums bei veränderlicher belastung.Sitzungberichte der Ak Wissenschaften Wien (Ser 2A) 1938; 147 (73).

6. Koiter WT. General theorems for elastic-plastic solids. In Progress in Solid Mechanics, Sneddon IN, Hill R, editors. North Holland : Amsterdam, 1960; $165 Đ 221$. 7. Johnson KL. A shakedown limit in rolling contact. Proceedings of the Forth US National Congress of Applied Mechanics, 1962; 971-975.

8. Sharp RW, Booker, JR. Shakedown of pavements under moving surface loads. J Transp Eng 1984; 110 : 1-14. 
9. Raad L, Weichert D, Najm W. Stability of multilayer systems under repeated loads. Trans Res B (NRC), TRB 1988; (1207): 181-6.

1. Yu HS, Hossain MZ. Lower bound shakedown analysis of layered pavements using discontinuous stress fields.Comput Method Apple M 1998; 167 (3-4) : 209 222.

2. Raad L, Weichert D, Haidar A. Analysis of full-depth asphalt concrete pavements using shakedown theory. Trans Res B (NRC), TRB 1989; (1227): 53-65.

3. Shiau S, Yu HS. Load and displacement prediction for shakedown analysis of layered pavements. Transp Res Record : J Trans Res B 2000; 1730 : 117-124.

4. Krabbenhøft K, Lyamin AV, Sloan SW. Shakedown of a cohesive-frictional halfspace subjected to rolling and sliding contact. Int J Solids Struct 2007; 44 (11-12) : 39984008.

5. Nguyen AD, Hachemi A, Weichert D. Application of the interior-point method to shakedown analysis of pavements. Int J Numer Anal Met 2008; 75 (4): 414-39.

6. Zhao J, Sloan SW, Lyamin AV, Krabbenhøft K. Bounds for shakedown of cohesive-frictional materials under moving surface loads. Int J Solids Struct 2008; 45 (11-12) : 3290-3312.

1. Yu HS, Wang J. Three-dimensional shakedown solutions for cohesive-frictional materials under moving surface loads. Int J Solids Struct 2012; 49 (26) : 3797-3807.

2. Wang J, Yu HS. Shakedown analysis for design of flexible pavements under moving loads. Road Mater Pavement 2013b; 14 (3) : 703-722.

3. Wang J, Yu HS. Three-dimensional shakedown solutions for anisotropic cohesivefrictional materials under moving surface loads. Int J Numer Anal Met 2014; 38 (4) : 331348.

4. Yu HS, Wang J, Liu S. Three-Dimensional Shakedown Solutions for CrossAnisotropic Cohesive-Frictional Materials under Moving Loads. In Direct Methods for Limit and Shakedown Analysis of Structures 2015; p.299-313. Springer International Publishing.

5. Ponter ARS, Hearle AD, Johnson KL. Application of the kinematical shakedown theorem to rolling and sliding point contacts. J Mech Phys Solids 1985; 33 (4) : 339-362.

6. Collins IF, Cliffe PF. Shakedown in frictional materials under moving surface loads. Int J Numer Anal Met 1987; 11 (4) : 409-420.

7. Boulbibane M, Collins IF, Ponter ARS, Weichert D. Shakedown of unbound pavements. Road Mater Pavement 2005; 6 (1) : 81-96.

8. Boulbibane M, Ponter ARS. Extension of the linear matching method to geotechnical problems. Comput Method Appl M 2005; 194 (45-47) : 4633-4650.

9. Li HX, Yu HS. A nonlinear programming approach to kinematic shakedown analysis of frictional materials. Int J Solids Struct 2006; 43 (21) : 6594-6614.

10. Li HX. Kinematic shakedown analysis under a general yield condition with nonassociated plastic flow. Int J Mech Sci 2010; 52 (1) : 1-12.

11. Lade $P$, Nelson $R$, Ito $Y$. Nonassociated flow and stability of granular materials. J Eng Mech-ASCE 1987; 113 (9) : 1302-1318.

12. Lade P, Pradel D. Instability and plastic flow of soils. I : Experimental observations. J Eng Mech-ASCE 1990; 116 (11) : 2532-2550.

13. Boulbibane $M$, Weichert $D$. Application of shakedown theory to soils with non associated flow rules. Mech Res Commun 1997; 24 (5) : 513-519.

14. Nguyen AD. Lower-bound shakedown analysis of pavements by using the interior point method, Ph.D. thesis, RWTH Aachen Unviversity, Germany, 2007.

15. Johnson KL. Contact Mechanics. Cambridge University Press, 1985.

16. Menetrey $P$, and Willam, K. J. Triaxial failure criterion for concrete and its generalization. ACI Structure J 1995; 92 (3) : 311-318.

17. Abaqus 6.13 User's guide. SIMULIA. 2013.

18. Radovsky B, Murashina N. Shakedown of subgrade soil under repeated loading. Transp Res Record: J Trans Res B 1996; 1547 : 82-88.

19. Liu S, Wang J, Yu HS, Wanatowski D. Shakedown of layered pavements under repeated moving loads. Geotechnical Specią1 Publications, ASCE 2014; 239 , p. 179-188. 
35. Brown SF. Soil Mechanics in Pavement Engineering. Geotechnique 1996; 42(3) : 383426.

1. Davis EH. Theories of plasticity and the failure of soil masses. In Progress

in Solid Mechanics, Lee KI, editors. London: Butterworth, 1968; 341-380.

2. Drescher A, Detournay E. Limit load in translational failure mechanisms for associative and non-associative materials. Geotechnique 1993; 43 (3) : 443-56.

3. Sloan S. Geotechnical stability analysis. Geotechnique 2013; 63 (7) : 531-571.

4. Michalowski RL. An estimate of the influence of soil weight on bearing capacity using limit analysis. Soils Found 1997; 37 (4) : 57-64.

5. Silvestri V. A limit equilibrium solution for bearing capacity of strip foundations on sand. Can Geotech J 2003; 40 : 351-361.

6. Shiau J, Lyamin A, and Sloan S. Bearing capacity of a sand layer on clay by Finite Element limit analysis. Can Geotech J 2004; 40 (5) : 900-915. 